University of Nebraska - Lincoln

DigitalCommons@University of Nebraska - Lincoln

USDA Wildlife Services - Staff Publications

U.S. Department of Agriculture: Animal and Plant Health Inspection Service

2017

Estimating population density for disease risk assessment: The importance of understanding the area of influence of traps using wild pigs as an example

\author{
Amy J. Davis \\ USDA National Wildlife Research Center, Amy.J.Davis@usda.gov \\ Bruce Leland \\ USDA National Wildlife Research Center \\ Michael J. Bodenchuk \\ USDA National Wildlife Research Center, michael.j.bodenchuk@usda.gov \\ Kurt C. VerCauteren \\ USDA-APHIS-Wildlife Services, kurt.c.vercauteren@usda.gov \\ Kim M. Pepin \\ USDA/APHIS/WS National Wildlife Research Center, kim.m.pepin@aphis.usda.gov
}

Follow this and additional works at: https://digitalcommons.unl.edu/icwdm_usdanwrc

Part of the Life Sciences Commons

Davis, Amy J.; Leland, Bruce; Bodenchuk, Michael J.; VerCauteren, Kurt C.; and Pepin, Kim M., "Estimating population density for disease risk assessment: The importance of understanding the area of influence of traps using wild pigs as an example" (2017). USDA Wildlife Services - Staff Publications. 1949.

https://digitalcommons.unl.edu/icwdm_usdanwrc/1949

This Article is brought to you for free and open access by the U.S. Department of Agriculture: Animal and Plant Health Inspection Service at DigitalCommons@University of Nebraska - Lincoln. It has been accepted for inclusion in USDA Wildlife Services - Staff Publications by an authorized administrator of DigitalCommons@University of Nebraska - Lincoln. 


\title{
Estimating population density for disease risk assessment: The importance of understanding the area of influence of traps using wild pigs as an example
}

\author{
Amy J. Davis ${ }^{\mathrm{a}, *}$, Bruce Leland $^{\mathrm{b}}$, Michael Bodenchuk ${ }^{\mathrm{b}}$, Kurt C. VerCauteren ${ }^{\mathrm{a}}$, \\ Kim M. Pepin ${ }^{a}$ \\ a National Wildlife Research Center, Wildlife Services, Animal Plant Health Inspection Service, United States Department of Agriculture, 4101 Laporte Ave., \\ Fort Collins, CO, USA \\ ${ }^{\mathrm{b}}$ Wildlife Services, United States Department of Agriculture, San Antonio, TX, USA
}

\section{A R T I C L E I N F O}

\section{Article history:}

Received 7 October 2016

Received in revised form 12 January 2017

Accepted 5 April 2017

\section{Keywords:}

Density

Management

Sus scrofa

Trapping

Wild pigs

Wildlife disease

\begin{abstract}
A B S T R A C T
Population density is a key driver of disease dynamics in wildlife populations. Accurate disease risk assessment and determination of management impacts on wildlife populations requires an ability to estimate population density alongside management actions. A common management technique for controlling wildlife populations to monitor and mitigate disease transmission risk is trapping (e.g., box traps, corral traps, drop nets). Although abundance can be estimated from trapping actions using a variety of analytical approaches, inference is limited by the spatial extent to which a trap attracts animals on the landscape. If the "area of influence" were known, abundance estimates could be converted to densities. In addition to being an important predictor of contact rate and thus disease spread, density is more informative because it is comparable across sites of different sizes. The goal of our study is to demonstrate the importance of determining the area sampled by traps (area of influence) so that density can be estimated from management-based trapping designs which do not employ a trapping grid. To provide one example of how area of influence could be calculated alongside management, we conducted a small pilot study on wild pigs (Sus scrofa) using two removal methods 1) trapping followed by 2) aerial gunning, at three sites in northeast Texas in 2015. We estimated abundance from trapping data with a removal model. We calculated empirical densities as aerial counts divided by the area searched by air (based on aerial flight tracks). We inferred the area of influence of traps by assuming consistent densities across the larger spatial scale and then solving for area impacted by the traps. Based on our pilot study we estimated the area of influence for corral traps in late summer in Texas to be $\sim 8.6 \mathrm{~km}^{2}$. Future work showing the effects of behavioral and environmental factors on area of influence will help mangers obtain estimates of density from management data, and determine conditions where trap-attraction is strongest. The ability to estimate density alongside population control activities will improve risk assessment and response operations against disease outbreaks.
\end{abstract}

Published by Elsevier B.V.

\section{Introduction}

Population density is an important determinant of disease dynamics due to its impact on contact rates (McCallum et al., 2001; Meng et al., 2009; Penrith et al., 2011; Pearson et al., 2016). However, in wildlife populations densities are often unknown, difficult to measure efficiently, and dynamic, which complicates risk assessment. Although there are many methods for estimating

\footnotetext{
* Corresponding author.

E-mail address: Amy.J.Davis@aphis.usda.gov (A.J. Davis).
}

abundance of wildlife populations (e.g., mark-recapture, distance sampling; reviewed in Williams et al. (2011)), removal sampling is the most efficient method to use alongside population management activities (Zippin, 1958; Farnsworth et al., 2002), because it only requires data on the removal and sampling effort. Other methods for estimating abundance often require additional manipulations in addition to management (e.g., tagging and release of animals). Using removal models, culling data can be used to estimate abundance directly.

Using a grid-based trapping design, area sampled is often taken to be the area of the grid plus some buffer around it. With this type of grid design, abundance can easily be converted to density 
by dividing by the area sampled. However, it can be challenging to infer density using trap data collected during routine management activities because the design can involve only a few traps per property at a time with inconsistent trapping effort. In this type of sampling design, the area impacted by the traps is difficult to assess, precluding conversion of abundance to density. Knowing the spatial extent to which individual traps attract animals, hereafter the 'area of influence', would provide the key denominator in converting abundance to density on a trap-by-trap basis. Other benefits of quantifying density over abundance is that it is a more explicit assessment of the population status in a management area and is comparable among management areas of different sizes.

Wild pigs (Sus scrofa) are globally widespread, geographically expanding, and may occur at low to high densities (Engeman et al., 2003; Bevins et al., 2014), and transmit a variety of pathogens which can be devastating to livestock industries (Meng et al., 2009; Széll et al., 2012; Pearson et al., 2016). As such, lethal removal is frequently employed to mitigate the risks that wild pigs pose to livestock and agriculture. One of the most commonly used management strategies for removing wild pigs to decrease densities/abundances is trapping (West et al., 2009). However, few studies have quantified abundance of wild pigs before and after trapping programs, resulting in a poor understanding of the effectiveness of different trapping strategies to decrease densities wild pig populations. Understanding wild pig densities over time and the effectiveness of different trapping strategies is critical in guiding allocation of management resources in prevention and response to disease outbreaks.

Our objective was to demonstrate a method for estimating the area of influence of traps using management-based data. The sample sizes used in our pilot study our small, thus we did not aim to provide robust estimates of area of influence. Rather, we aimed to highlight the importance of measuring area of influence for the purpose of motivating wildlife managers and researchers into quantifying it and identifying factors that affect it. We argue that quantification of factors determining area of influence will not only enable more accurate estimates of density for disease risk assessment but also help with planning efficient management strategies for prevention and control of disease.

\section{Study area}

We conducted wild pig removal in two counties, Baylor and Wilbarger, in northeast Texas during late summer 2015. The study area is in the tropical/subtropical steppe ecoregion division. The habitat in the study area consisted primarily of mesquite (Prosopis spp.) covered rangeland with some agricultural cropland. Riparian areas were dominated by mixed hardwoods.

\section{Methods}

We placed three corral traps (consisting of three 1.82-m panels arranged in a tear drop or circular shape; Lewis et al., 2009) approximately $20 \mathrm{~km}$ apart (Fig. 1). We selected trap locations in areas of known pig activity according to expert opinion in order to maximize capture rates. We pre-baited, with whole corn, the sites for five days prior to trapping. We placed motion-activated cameras (M-880i infrared mini game camera, Moultrie ${ }^{\circledR}$, Moultrie, Georgia, USA) focused on the bait piles. The traps had continuous-catch, or 'rooter', doors and were triggered with a tripwire (Lewis et al., 2009). Trapping was conducted from 25 August to 7 September 2015 (i.e., traps were open for 7 days). Once trapped, captured pigs were humanely euthanized via gunshot to the brain (AVMA Guidelines for the Euthanasia of Animals: 2013). We then reset and rebaited traps.
Two weeks after trapping, we used aerial gunning from helicopters to remove wild pigs from each area. The objective was to fly intensively in areas much larger than the area a trap influences around each trap site and to remove all pigs encountered. Each pilot used a different search strategy based upon previous successful gunning experiences; these included strategic searching, spiraling out from the trap, and line transect searching. The search methods were documented in their flight tracks (Fig. 1) allowing us to accurately assess the area searched by each pilot. During these flights, any pigs that were seen but not killed were also recorded. Flights were conducted within a week after trapping to try to ensure a closed population (no births, deaths, immigration or emigration during the study). Using ArcMap (ESRI, 2015) software, we created polygons with an average $500 \mathrm{~m}$ buffer around the aerial flight tracks (to account for areas on both sides of the helicopter being searched) centered at each trap and calculated the area searched by flight. We calculated the observed density for each site as the total number killed and seen but not killed $\left(N_{\text {aerial }}\right)$ divided by the area searched $\left(\hat{A_{\text {aerial }}}\right)$.

We estimated abundance from the trapping data using a removal model framework (Farnsworth et al., 2002; Royle and Dorazio, 2006). Removal models assume a constant capture rate (per effort) and estimate the capture rate and population size based on an observed reduction in captures. We used a hierarchical Bayesian approach that employs a standard removal framework while accounting for variation in capture effort (Davis et al., 2016). For trapping data we used the number of nights that traps were active prior to a capture event as the amount of effort. Removal models require multiple capture events in this case they are the multiple trigger events of traps. When a trap was triggered the number of nights it had been active prior to being triggered was the effort and the number captured was recorded. At the end of the trapping period the number of nights since the last trigger event was recorded and the final capture number was recorded (if not triggered on the last night than zero was the number captured).

We assumed a consistent density at the scale in which the aerial work was conducted. The trapping method used baiting which may pull in individuals from a wider area creating an artificially high density at the trap site. However, by knowing the 'region-wide' density we can calculate the area influenced by the trap (i.e., the higher the artificial density the larger the area being influenced). Using Eq. (1), we solved for the area influenced by trapping $\left(\hat{A_{\text {trap }}}\right)$, where $\hat{N_{\text {trap }}}$ is the abundance estimated from trapping, and $\hat{A_{\text {trap }}}$ is the area influenced by trapping or aerial removal methods. Using Eq. (2), we converted the area influenced by the trap to the radius (r) of the area of influence for ease of comparison.

$\frac{N_{\text {aerial }}}{A_{\text {aerial }}}=\frac{N_{\text {trap }}}{A_{\text {trap }}}$

$r=\sqrt{\frac{\hat{A_{\text {trap }}}}{\pi}}$

\section{Results}

We captured 2, 7, and 8 pigs at the three different trap sites respectively (Table 1 ). The estimated abundance of wild pigs around those traps are 7.9, 11.2, and 25.2 respectively (see Table 1 for credible intervals). We removed 152,181 , and 151 pigs by aerial gunning at the three sites (Table 1 ). There were also 6,0 , and 10 pigs that were seen but not removed by aerial gunning at the respective sites (i.e., $\sim 97 \%$ of pigs seen from air were removed). The areas impacted by the aerial gunning were 180,138 , and $58 \mathrm{~km}^{2}$ respectively. The densities calculated from the aerial gunning were 0.88 , 1.31 , and $2.78 \mathrm{pigs} / \mathrm{km}^{2}$. Using these densities we calculated the area impacted by the traps (Fig. 1) and the respective area of influ- 


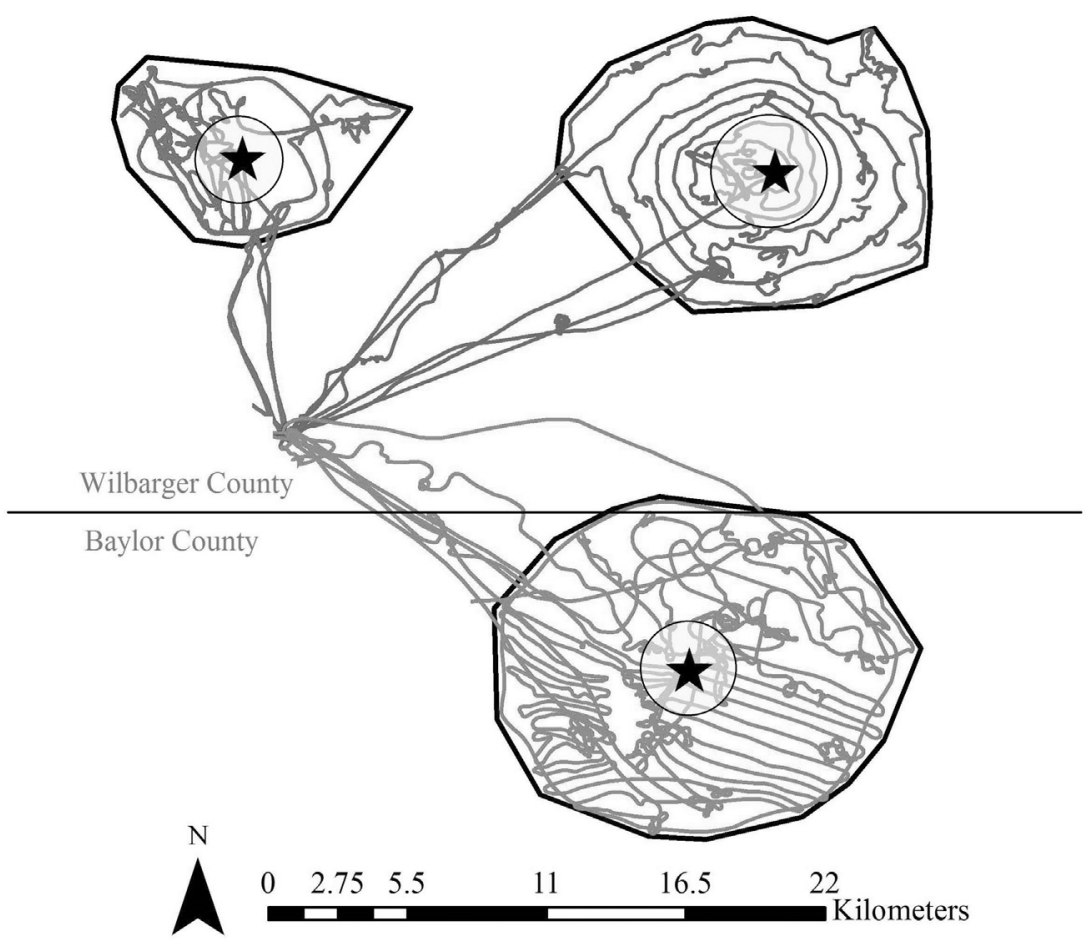

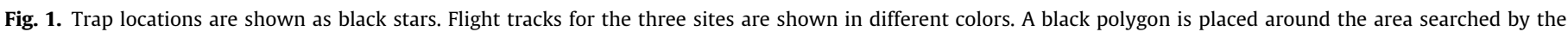

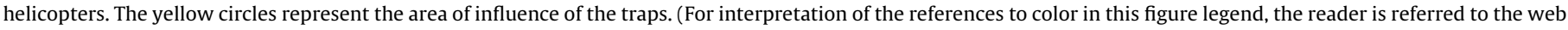
version of this article.)

ence for each trap. Our results suggest that traps had an area of influence of $9.0,8.5,8.2 \mathrm{~km}^{2}$ respectively.

\section{Discussion}

Removal sampling is commonly used in wildlife population management for estimating population abundance before and after management efforts (Zippin, 1958; Farnsworth et al., 2002), and is particularly appropriate for invasive species or disease control where reducing populations is the management objective (Ramsey et al., 2009; Chee and Wintle, 2010; Davis et al., 2016). Removals by aerial gunning can be very effective, but is an expensive approach and is impractical in some areas (e.g., heavy forest coverage). Corral trapping is suitable across a variety of landscapes and has the potential to remove large groups of animals at a time. For trap-based removal sampling conducted as part of disease or damage prevention management programs, it is uncommon to know the size of the area being sampled and few traps may be used during a trapping period. Thus, determining the area of influence (i.e. the area sampled by a trap, which is ultimately determined by the attraction power of lures and movement behavior of the target species) can allow managers to determine the spatial extent to which they are effective in attracting animals for removal. Because abundance estimates from traps are limited to the area of influence of those traps which may be quite small (as we found here), trap-based abundance estimates are unlikely to reflect the complete area of interest to managers. Knowing the area impacted by a trap in a particular situation will allow conversion of abundance estimates to density, a better indicator of population status and disease risk in the area.

From our study we were able to estimate the area of influence at three trap sites. The area of influence for each site was around $8.87 \mathrm{~km}^{2}$, even though the densities varied from 0.88 to 2.78 pigs $/ \mathrm{km}^{2}$. Despite only examining three sites (one occasion each), the consistency of our estimates of area of influence may suggest a similarity in the attractiveness of individual traps under similar circumstances (e.g., habitat, season, trapping duration, personnel). However, additional research would be needed to confirm this. Variation in conditions could result in variation in the area of influence. The area of influence may vary due to a combination of biological limitations such as movement behavior (Baber and Coblentz, 1986; Saunders and McLeod, 1999; Fischer et al., 2016), or environmental factors such as resource availability (Saunders et al., 1993; Caley, 1994), weather (Wyckoff et al., 2006), and trap type or duration of trapping (Caley, 1994; Williams et al., 2011). Understanding effects of these factors on area of influence is not only relevant to obtaining better estimates of disease control impacts but also to planning efficient resource allocation for risk assessment and responding to disease outbreaks.

Previous studies have shown that baiting influences the home range size and movement of wildlife populations (Cooper et al., 2006; Sahlsten et al., 2010; Jerina, 2012). Therefore, it is probable that wild pigs in our study area modified their movement in relation to the trapping efforts as baiting was used. This may have resulted in artificially high densities of wild pigs around the trap sites compared to the areas covered by aerial removal efforts because individuals may have been attracted to the baited areas from farther than their normal home-range size. This attractiveness is precisely the aspect we are interested in to accurately assess the area of influence of a trap. Therefore, it is vital to use an estimate of density that is not influenced by an attractant (such as aerial surveys) to get a sense of the underlying area of influence for a trap.

Other studies that estimate density from trapping data used information about animal movement patterns to determine a buffer around the gridded trapping area (Wilson and Anderson, 1985; Ivan et al., 2013). A commonly used buffer is the mean maximum dis- 


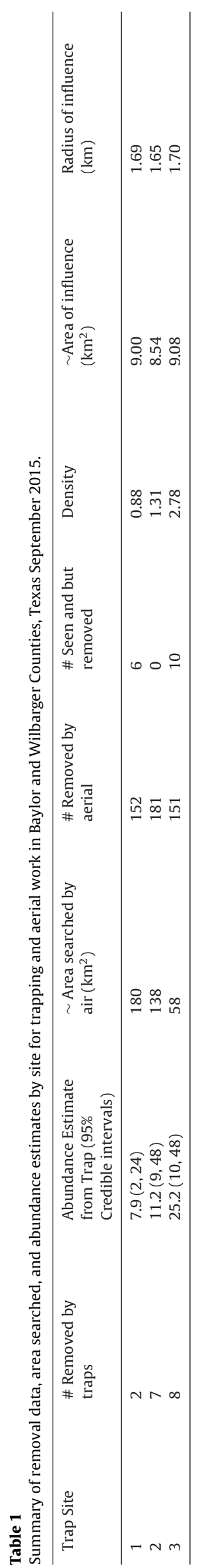

tance moved (MMDM) (Wilson and Anderson, 1985). Estimates for the MMDM for wild pigs from camera trap data were $0.3-0.9 \mathrm{~km}$ (Keiter et al., In Review). These estimates are less than the estimates of the radius of the area of influence we estimated $(\sim 1.65 \mathrm{~km})$. However, these MMDM estimates may be biased low as the maximum distance moved is likely larger than the farthest two cameras on which an individual is detected. The density estimates that we observed $\left(0.88-2.78\right.$ wild pigs $\left./ \mathrm{km}^{2}\right)$ were within the range of density estimates for wild pigs in Texas from other studies (0.68-6.25 wild pigs $/ \mathrm{km}^{2}$; Adkins and Harveston, 2007; Timmons et al., 2012).

Trap placements are usually intended to maximize the probability of capturing animals. If trap placements are unfavorable and result in few captures, the area of influence for that trap would be relatively small. The attractiveness of traps in our small study was fairly consistent, which may be, in part, due to the consistent strategy of the manager in our study. However, it is important to keep in mind that managers' intuitions on trap placement can impact the area of influence, and personnel may be an important factor that influences the area of influence.

The main objective of our study was to highlight the importance of area of influence as a key quantity in determining population density, rather than to obtain precise estimates of these metrics for wild pig trapping programs. Nonetheless we believe there is value in the perspective and approach that our pilot study provides for motivating future research and management towards collecting the appropriate data for improving population knowledge for disease prevention and response.

Most management efforts may not inherently involve a method to estimate the area of influence. However, when possible methods such as this can add to the body of literature and will help inform the relationship between external factors and the area of influence. In addition to study designs similar to ours, the area of influence could be estimated from camera-trap data or spatially-explicit data (as described above), or from studies that have GPS collared individuals prior to trapping events. Investigations into the different factors that determine the area of influence of a trap will help elucidate the effectiveness of management strategies (e.g., how much a population is reduced by management actions) and provide guidance for making future management decisions (e.g., what types of baits, traps, seasonal or habitat effects impact the area of influence of a trap and hence efficiency at removing individuals to curb disease transmission).

\section{Acknowledgments}

Thanks to the Wildlife Services: David Pipkin, Zachary May, Michael Ward, Peter Bland, Miller Walker, Billy Roe, Tracy Muir, Kelly Spinks, Thomas Taylor, and Cole Taylor who conducted the work. Any use of trade, firm, or product names is for descriptive purposes only and does not imply endorsement by the U.S. government. This research did not receive any specific grant from funding agencies in the public, commercial, or not-for-profit sectors.

\section{References}

Adkins, R.N., Harveston, L.A., 2007. Demographic and spatial characteristics of feral hogs in the Chihuahuan Desert, Texas. Hum.-Wildl. Interact., 83.

Baber, D.W., Coblentz, B.E., 1986. Density, home range, habitat use, and reproduction in Feral Pigs on Santa Catalina Island. J. Mammal. 67, 512-525.

Bevins, S.N., Pedersen, K., Lutman, M.W., Gidlewski, T., Deliberto, T.J., 2014

Consequences associated with the recent range expansion of nonnative Feral Swine. BioScience 64, 291-299.

Caley, P., 1994. Factors affecting the success rate of traps for catching feral pigs in a tropical habitat. Wildl. Res, 21, 287-292.

Chee, Y.E., Wintle, B.A., 2010. Linking modelling, monitoring and management: an integrated approach to controlling overabundant wildlife. J. Appl. Ecol. 47, 1169-1178. 
Cooper, S.M., Owens, M.K., Cooper, R.M., Ginnett, T.F., 2006. Effect of supplemental feeding on spatial distribution and browse utilization by white-tailed deer in semi-arid rangeland. J. Arid Environ. 66, 716-726.

Davis, A.J., Hooten, M.B., Miller, R.S., Farnsworth, M.L., Lewis, J., Moxcey, M., Pepin, K.M., 2016. Inferring invasive species abundance using removal data from management actions. Ecol. Appl. 26 (7), 2339-2346.

Engeman, R.M., Smith, H.T., Shwiff, S.A., Constantin, B., Woolard, J., Nelson, M., Griffin, D., 2003. Prevalence and economic value of feral swine damage to native habitat in three Florida state parks. Environ. Conserv. 30, 319-324.

ESRI, 2015. ArcGIS Desktop: version 10.4.0.5524. In: Environmental Systems Research Institute. Redlands, CA USA.

Farnsworth, G.L., Pollock, K.H., Nichols, J.D., Simons, T.R., Hines, J.E., Sauer, J.R., Brawn, J., 2002. A removal model for estimating detection probabilities from point-count surveys. Auk 119, 414-425.

Fischer, J.W., McMurtry, D., Blass, C.R., Walter, W.D., Beringer, J., VerCauteren, K.C., 2016. Effects of simulated removal activities on movements and space use of feral swine. Eur. J. Wildl. Res., 1-8.

Ivan, J.S., White, G.C., Shenk, T.M., 2013. Using simulation to compare methods for estimating density from capture-recapture data. Ecology 94, 817-826.

Jerina, K., 2012. Roads and supplemental feeding affect home-range size of Slovenian red deer more than natural factors. J. Mammal. 93, 1139-1148.

Keiter D.A., Davis A.J., Rhodes O.E.J., Cunningham F.L., Kilgo J.C., Pepin K.M., Beasley J., In Review. Impact of animal movement on common methods of estimating population density. Scientific Reports, In Press.

Lewis, C., Berg, M., Cathey, J.C., Gallagher, J., Dictson, N., McFarland, M., 2009. Corral Traps for Capturing Feral Hogs. Texas A\&M University, Texas AgriLife Extension Service.

McCallum, H., Barlow, N., Hone, J., 2001. How should pathogen transmission be modelled? Trends Ecol. Evol. 16, 295-300.

Meng, X.J., Lindsay, D.S., Sriranganathan, N., 2009. Wild boars as sources for infectious diseases in livestock and humans. Philos. Trans. R. Soc. B: Biol. Sci. 364, 2697-2707.

Pearson, H.E., Toribio, J.-A.L.M.L., Lapidge, S.J., Hernández-Jover, M., 2016. Evaluating the risk of pathogen transmission from wild animals to domestic pigs in Australia. Prev. Vet. Med. 123, 39-51.
Penrith, M.L., Vosloo, W., Mather, C., 2011. Classical swine fever (hog cholera): review of aspects relevant to control. Transbound. Emerg. Dis. 58, 187-196.

Ramsey, D.S.L., Parkes, J.P., Morrison, S.A., 2009. Quantifying eradication success: the removal of feral pigs form Santa Cruz Island, California. Conserv. Biol. 23, 449-459.

Royle, J.A., Dorazio, R., 2006. Hierarchical models of animal abundance and occurrence. JABES 11, 249-263.

Sahlsten, J., Bunnefeld, N., Månsson, J., Ericsson, G., Bergström, R., Dettki, H., 2010 Can supplementary feeding be used to redistribute moose Alces alces? Wildl. Biol. 16, 85-92.

Saunders, G., McLeod, S., 1999. Predicting home range size from the body mass or population densities of feral pigs, Sus scrofa (Artiodactyla: suidae). Austr. J. Ecol. 24, 538-543.

Saunders, G., Kay, B., Nicol, H., 1993. Factors affecting bait uptake and trapping success for feral pigs (Sus scrofa) in Kosciusko National Park. Wildl. Res. 20 653-665

Széll, Z., Marucci, G., Ludovisi, A., Gómez-Morales, M.A., Sréter, T., Pozio, E., 2012. Spatial distribution of Trichinella britovi: T. spiralis and T. pseudospiralis of domestic pigs and wild boars (Sus scrofa) in Hungary. Vet. Parasitol. 183, 393-396.

Timmons, J.B., Mellish, J., Higginbotham, B., Griffin, J., Lopez, R.R., Sumrall, A., Cathey, J.C., Skow, K., 2012. Feral Hog Population Growth, Density, and Harvest in Texas. Texas A\&M, College Station, TX, USA.

West, B.C., Cooper, A.L., Armstrong, J.B., 2009. Managing wild pigs: a technical guide. Hum.-Wildl. Interact. Monogr. 1, 1-55.

Williams, B.L., Holtfreter, R.W., Ditchkoff, S.S., Grand, J.B., 2011. Trap style influences Wild Pig behavior and trapping success. J. Wildl. Manage. 75, 432-436.

Wilson, K.R., Anderson, D.R., 1985. Evaluation of two density estimators of small mammal population size. J. Mammal. 66, 13-21.

Wyckoff, C., Henke, S.E., Campbell, T., Ver Cauteren, K.C., 2006. Is trapping success of feral hogs dependent upon weather conditions? Proc. Vertebr. Pest Conf. 22, $370-372$.

Zippin, C., 1958. The removal method of population estimation. J. Wildl. Manage. 22, 82-90. 